\title{
An investigation into the management of the deep carious lesion by general dental practitioners in the UK
}

Sheena Patel, ${ }^{1}$ Peter Fine, ${ }^{* 1}$ Mandeep Shukla, ${ }^{1}$ Robert Blizard ${ }^{1}$ and Albert Leung ${ }^{1}$

\section{Key points}

The reader will learn about decision making in cavity design and will be able to assess their level of current knowledge.
The reader will be able to modify their clinical technique if appropriate.
The reader will learn about suitable materials when treating a deep carious lesion.

\begin{abstract}
Objectives As techniques and dental materials have evolved, the management of deep carious lesions has also changed. This study investigated how UK-based general dental practitioners (GDPs) managed deep carious lesions in permanent, vital teeth and factors that influence their choices.

Methods This mixed-method study employed an online questionnaire as its primary source of quantitative data collection. The questionnaire enquired about GDPs': a) demographics; b) working environment; and c) whether they had postgraduate training that covered caries management/minimally invasive dentistry (MID). Respondents were presented with a clinical case to elicit qualitative data. Relevant questions were asked in order to examine current practice and explore treatment among the respondents.
\end{abstract}

Results In total, 239 responses were received. Overall, 168 (70\% [95\% Cl 64\%, 76\%]) of the respondents chose a partial caries removal technique, $155(69.3 \%$ [95\% Cl 60\%, 72\%]) used an adhesive restorative material and 205 (85.8\% [95\% Cl 81\%, 89\%]) advised fluoride adjuncts. However, rubber dam (75; 31.4\% [95\% Cl 26\%, 38\%]) and saliva testing $(17 ; 7.1 \%[95 \% \mathrm{Cl} 4 \%, 11 \%])$ were not routinely used. A significant relationship between those who had postgraduate training and those who chose partial caries removal as their treatment choice $\left(\chi^{2}=6.27 ; p=0.01\right)$ was noted. Respondents working in an NHS-based practice were significantly $\left(\chi^{2}=34.98 ; p<0.001\right)$ more likely to restore teeth with amalgam.

Conclusions There is an inconsistent management protocol when presented with a deep carious lesion, but partial caries removal is more widely adopted than previously reported. Rubber dam isolation was not routinely used when choosing to restore a deep carious lesion. Those who have had postgraduate training felt more confident in offering MID, so there is a clear need for further education to ensure its engagement.

\section{Introduction}

Regular, frequent intake of fermentable dietary carbohydrates results in the oral environment becoming more favourable for aciduric (acidwithstanding) and acidogenic (acid-producing) bacteria to thrive within the stagnating biofilm. ${ }^{1}$ The shift in activity within the biofilm leads to an increased production of organic acids and a net mineral loss from the dental hard tissue (demineralisation), thus resulting in a carious lesion. ${ }^{2}$ Remineralisation occurs through

${ }^{1}$ University College London, Eastman Dental Institute, London, UK.

*Correspondence to: Peter Fine

Email address: p.fine@ucl.ac.uk

Refereed Paper.

Accepted 3 April 2021

https://doi.org/10.1038/s41415-022-3880-z saliva. This process, known as the 'ecologic plaque hypothesis,' 3 challenges the traditional measures of managing a carious lesion, both those that are confined to enamel and those that extend into dentine, with more contemporary techniques. Managing deep carious lesions in vital teeth is a significant challenge for general dental practitioners (GDPs). ${ }^{4}$ Removal of caries in close proximity to the pulp carries risks of pulpal inflammation and pain in a previously asymptomatic tooth. ${ }^{5}$

Leaving carious tooth tissue under a restoration was once considered a taboo. However, with scientific development, there is a better understanding about the caries process, ${ }^{6}$ the ability of the pulp to protect itself and the impact of patient factors on caries development and progression. This has also led to the development of new restorative materials and therefore the classical techniques for cavity design as recommended by G. V. Black in the late nineteenth century have largely been superseded.?

There has been a paradigm shift in the acceptable amount of carious tooth tissue that requires excavation. Leaving affected dentine and even infected dentine clear of the cavity periphery ${ }^{8,9,10,11}$ and sealing the tooth prevents the progression of the carious lesion, allowing reparative pulp-dentine complex reactions to take place, reducing the risk of pulpal exposure and conserving natural tooth structure. Contemporary dentistry focuses on prevention of caries and early detection. An evidence-based, more conservative approach to surgical caries intervention ${ }^{12}$ has also been recommended. Thus, there has been an evolution of the term 'minimally invasive dentistry' (MID), defined as 'a contemporary ultraconservative operative management 

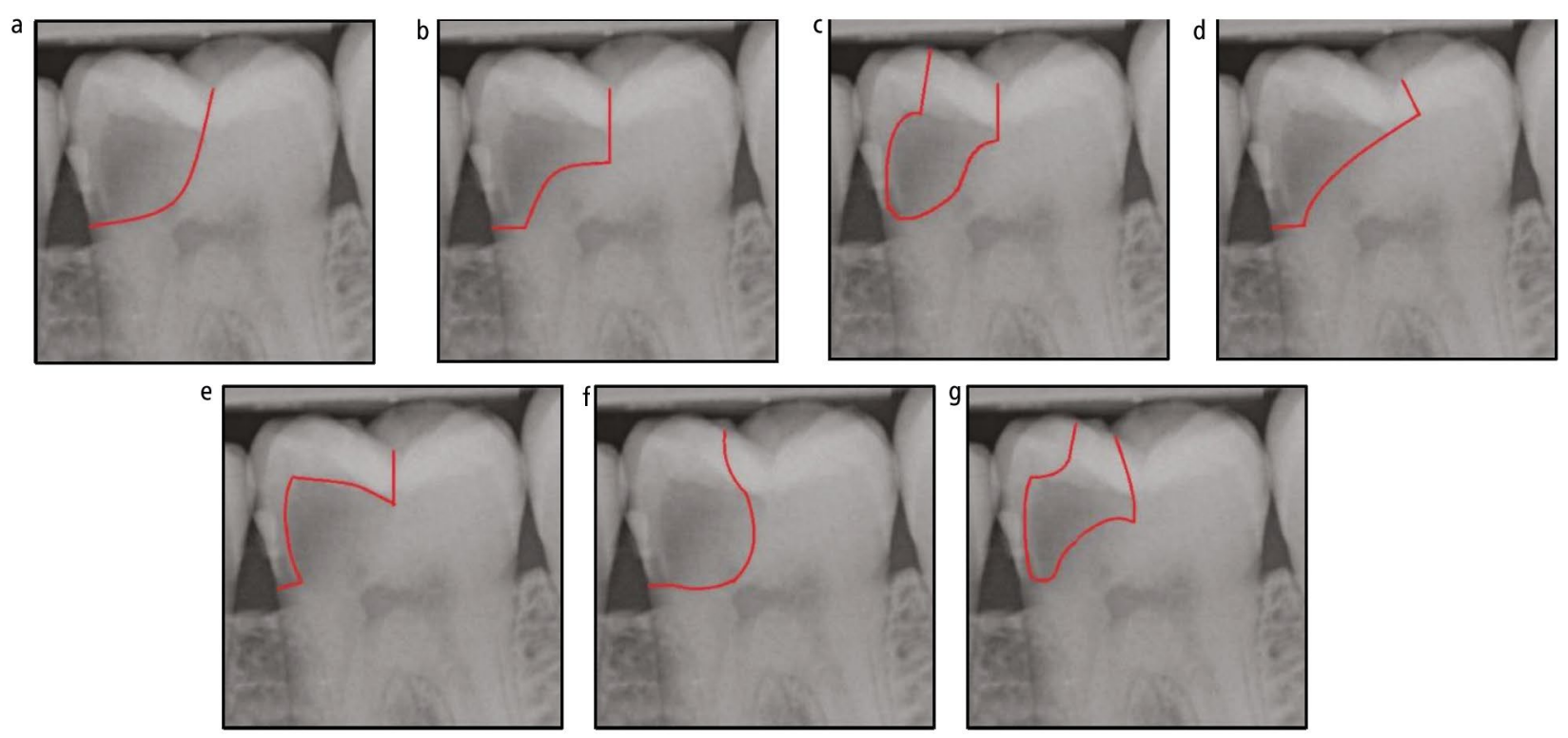

Fig. 1 a, b, c, d, e, f, g) Options of cavity preparation design given to respondents in response to the clinical scenario

of cavitated lesions requiring surgical intervention. ${ }^{11}$

The aim of MID is to prevent carious lesions from developing and where the lesions are already clinically established, prevent them from progressing, supplemented by promoting remineralisation of early lesions, for example using fluoride adjuncts to decrease the solubility of dental hard tissue to further reduce the risk of demineralisation. This would allow conservation of more natural tooth structure, thus maintaining aesthetics and strength. Deep carious lesions should be treated surgically with selective excavation as recommended at the International Caries Consensus Collaboration (ICCC) in 2016. ${ }^{2}$ The ICCC offered consistent, detailed terminology, recommendations on removal of carious tissue using clinical references to dentine hardness and recommendations in the management of cavitated carious lesions, enabling a greater understanding among the dental community.

There are a number of different selective excavation techniques and a large variety of adhesive restorative materials available, which poses a dilemma for GDPs.

The primary aim of this study was to investigate the management of a deep carious lesion by GDPs in the UK. For the purpose of this study, a deep carious lesion is one that extends radiographically, to the inner (pulpal) third of dentine, or from a clinical aspect, one that has a risk of pulp exposure. ${ }^{13}$ With preservation of pulp vitality being the ultimate goal when managing this type of lesion, it is important to assess if GDPs are adopting conservative strategies.
Additional objectives included assessment of the GDPs' confidence in their knowledge and understanding of the principles of MID and if patient-derived factors influenced GDP decisions.

Recent research ${ }^{4,14}$ has identified a disparity between awareness and knowledge of good practice and what is actually being practised by GDPs. It is important to assess the potential barriers to the implementation of evidence-based dentistry into dental practices when managing a deep carious lesion and how best to change them.

\section{Methods and materials}

This study was a questionnaire-based, crosssectional, mixed-method study with the survey instrument as an online questionnaire on Google Forms. Two independent pilot studies were conducted. Six different specialists (prosthodontists, endodontists and restorative specialists) completed one pilot study. The second pilot group comprised of seven GDPs. Minor changes were subsequently made to the questionnaire to ensure it could acquire the correct type of data and to eliminate ambiguity. ${ }^{15}$ A five-point Likert ${ }^{16}$ scale was used as part of the questionnaire design, in addition to some open questions encouraging a text response, some closed and some multiple choice. Qualitative data were collected from respondents' opinions related to the clinical scenario that formed part of the questionnaire.

The target population was GDPs in the UK. The online questionnaire included an information sheet outlining the aims of the study, with reassurances that all responses would be treated with confidence and anonymity. Participation in the study was voluntary.

A brief overview of the study with the link to the questionnaire was put on an online forum on Facebook, accessible to only dentists; 'For Dentists, By Dentists.

The 47-question questionnaire was divided into three sections:

1. GDPs demographic information, including their working environment and if they had undertaken postgraduate training that covered caries management

2. If respondents opted to restore the tooth, knowledge was evaluated by asking a series of questions on a scenario of a vital, asymptomatic lower first molar with a bitewing radiograph showing a radiolucent lesion deep into the dentine and in close proximity to the pulp. Ten clinically-based questions determined the extent to which respondents applied evidence-based MID principles to this clinical scenario. The questions included, but were not limited to: a) how they would treat this case and should a restorative option be selected, to choose a cavity design that they would perform representing the amount of tooth tissue they would remove and to the hardness of dentine that they would stop excavation (Fig. 1); b) techniques/instruments of choice; c) materials of choice to restore; and d) if they would 're-enter' the cavity. Optional open-ended questions were included so respondents could elaborate on their choices thus enhancing the qualitative data 
3. Five-point Likert scales were used to evaluate the respondent's level of agreement with regards to caries risk assessment, dietary habits assessment, use of fluoride and what patient factors may influence their management decision. They were also asked about how confident they felt in their knowledge of MID.
Sample size calculations were based on the scenario questions using this formula: (http://epitools.ausvet.com.au/content.

php? page $=$ SampleSize $) \mathrm{N}=(\mathrm{Z} 2 \times \mathrm{P}(1-\mathrm{P})) / \mathrm{e} 2$. With 42,000 registered dentists in the UK, we expected $50 \%$ of the respondents to score those questions correct; that is, in accordance with 'good practice' - 95\% confidence interval

\begin{tabular}{l|l}
$\begin{array}{l}\text { Table } 1 \text { Demography of samples } \\
\text { Sample size (N=239) }\end{array}$ & Mean (SD) or N (\%) \\
\hline Demographic & $35(8.2)$ \\
\hline Age (years) & $101(42.3 \%)$ \\
\hline Male sex & $2008(8.4)$ \\
\hline Year of qualification & $200(83.7 \%)$ \\
\hline UK qualified & $4.2(1.0)$ \\
\hline Days of work & $93(38.9 \%)$ \\
\hline Postgraduate training in caries management & $39(41.9 \%)$ \\
\hline Type of accreditation by postgraduate-trained (N= 93$)$ \\
\hline Continuing professional development (CPD)/other & $54(58.1 \%)$ \\
\hline University/formal & \multicolumn{2}{|l}{} \\
\hline Type of practice & $33(13.8 \%)$ \\
\hline Exclusively private & $31(12.9 \%)$ \\
\hline Mostly private & $36(15.1 \%)$ \\
\hline Mixed 50/50 & $112(46.9 \%)$ \\
\hline Mostly NHS & $14(5.9 \%)$ \\
\hline Exclusively NHS & $7(2.9 \%)$ \\
\hline Hospital & $6(2.5 \%)$ \\
\hline Other & \\
\hline &
\end{tabular}

Table 2 MID good practice categories answered correctly

\begin{tabular}{l|l|l} 
Sample size (N = 239) & N (\%) & $95 \% \mathrm{CI}$ \\
\hline Category & $168(70 \%)$ & $(64 \%, 76 \%)$ \\
\hline Good practice & $145(61 \%)$ & $(54 \%, 67 \%)$ \\
\hline Good practice: cavity design & $176(74 \%)$ & $(68 \%, 79 \%)$ \\
\hline Good practice: dentine texture & $158(66 \%)$ & $(60 \%, 72 \%)$ \\
\hline Good practice: restorative material & $75(31 \%)$ & $(26 \%, 38 \%)$ \\
\hline Good practice: rubber dam & $121(51 \%)$ & $(44 \%, 57 \%)$ \\
\hline Good practice: recall & $126(53 \%)$ & $(46 \%, 59 \%)$ \\
\hline Good practice: diet sheet & $99(41 \%)$ & $(35 \%, 48 \%)$ \\
\hline Good practice: referral to hygienist & $17(7 \%)$ & $(4 \%, 11 \%)$ \\
\hline Good practice: salivary testing & $205(86 \%)$ & $(81 \%, 89 \%)$ \\
\hline Good practice: advise fluoride adjuncts & & \\
\hline
\end{tabular}

(CI) of $\pm 7 \%$ desired precision. The required sample size number was calculated to be 196 .

\section{Data collection and analysis}

Data from the questionnaires were submitted from Google Forms onto an Excel spreadsheet and descriptive analysis carried out using SPSS statistics data editor (IBM Corp. Released 2017. IBM SPSS Statistics for Windows, Version 25.0. Armonk, NY: IBM Corp).

Mean and standard deviation (SD), proportion (\%) and 95\% CI were used as appropriate when analysing frequency distribution of univariate data in order to answer the primary research question. Bivariate analysis using measures of association were carried out to look for statistical significance in relationships of variables for the purpose of the secondary aims of this study. Group comparisons were carried out by chi-squared $\left(\chi^{2}\right)$, linear-by-linear $\left(\chi^{2 \text { lin }}\right)$, Fisher's exact test (FET) and analysis of variance (ANOVA) where appropriate.

Recommendations on minimally invasive caries removal, specific to a deep carious lesion, as published by the ICCC $^{2}$ were used as the 'good practice' criteria for statistical analysis.

A thematic approach to analyse qualitative data was used as patterns of meanings emerged across the rich data.

Research Ethics approval was granted by the University College London Research Ethics Committee, before commencing on this piece of work (UCL Ethics No: 6552/006).

\section{Results}

A total of 244 questionnaires were completed and returned, surpassing the inclusion criteria for this study. Five questionnaires were excluded; four were from individuals outside the UK and one was completed by a specialist. The descriptive statistics for demographic characteristics of respondents are presented in Table 1 . The median year of qualification was 2008 with $38.9 \%(n=93)$ that had postgraduate training where caries management was part of the curriculum. The majority of respondents, $52.7 \%(n=126)$, worked in either an exclusively or mostly NHS-based practice.

To determine the extent of adherence to evidence based MID principles, each category was analysed (Table 2). Overall, $86 \%(\mathrm{n}=205)$ of respondents reported to show good practice when advising fluoride adjuncts. Only $7 \%$ $(n=17)$ of respondents reported to show good practice to carry out saliva testing. In total, $70 \%(\mathrm{n}=167)$ chose a partial caries removal 
technique and similar proportions of $74 \%$ $(\mathrm{n}=177)$ stopped caries excavation to the appropriate dentine hardness. Additionally, $66 \%(n=158)$ chose to restore using an adhesive restorative material and $61 \%(n=146)$ chose an appropriate partial caries cavity design, while $31 \%(n=74)$ reported to show good practice by using a rubber dam when restoring.

The mean number of MID good practice questions answered correctly was 5.4 and follows a normal distribution, slightly skewed in a positive direction. Overall, $51.9 \%$ $(\mathrm{n}=124)$ respondents answered at least six of the ten MID good practice questions correctly. There were only six respondents (2.5\%) that answered all ten questions correctly and two respondents who did not answer any correctly.

The ten categories of good practice were used to create a realistic MID 'score of good practice' ('GP score') for statistical analysis. Cronbach's alpha ${ }^{17}$ of the 'GP score' was 0.7. Since this is at the lower limit of utility for a unitary scale, a preliminary principle components (PC) analysis was carried out and it revealed that there were three potentially different dimensions underlying the responses to the selected questions:

1. Treatment choice, cavity preparation design, dentine texture at the point to stop excavation

2. Material choice, use of rubber dam, use of saliva testing

3. Recall time, give diet sheet, refer to hygienist, advise use of fluoride.

\section{Univariate analysis}

In total, $41.8 \%(\mathrm{n}=100)$ of respondents would partially remove soft dentine and restore the tooth without re-entering. One respondent ( $0.4 \%)$ opted to extract the tooth, while $23 \%$ $(\mathrm{n}=55)$ of respondents chose to remove the entire carious lesion and restore (Table 3 ).

Overall, $49.6 \%(\mathrm{n}=113)$ of respondents reported that they would stop caries excavation once they reach 'firm dentine', defined as 'physically resistant to hand excavation requiring some pressure to be exerted through an instrument to lift it.' ${ }^{2}$ When asked to choose which direct restorative material they would prefer, $25.9 \%(\mathrm{n}=59)$ reported to use a layered closed sandwich restoration technique of glass ionomer cements (GIC) and resin composite and $23.7 \%(\mathrm{n}=54)$ chose amalgam (Table 4$)$.

When asked if any additional steps would be undertaken, some common themes were identified among the 109 comments (Table 5)

Table 3 Treatment choice by GDPs of how to manage carious lesion

\begin{tabular}{l|l} 
Sample size $(\mathbf{N}=\mathbf{2 3 9})$ & $\mathbf{N}(\%)$ \\
\hline Treatment choice & $55(23.0 \%)$ \\
\hline Removal of all the carious lesion and restore & $68(28.5 \%)$ \\
\hline $\begin{array}{l}\text { Partial removal of soft dentine and restore the tooth, followed by re-opening after a } \\
\text { period of time to excavate the remaining caries and re-restore the tooth }\end{array}$ & $100(41.8 \%)$ \\
\hline Partial removal of soft dentine and restore the tooth, and not re-enter the tooth & $7(2.9 \%)$ \\
\hline Root canal treatment & $1(0.4 \%)$ \\
\hline Extract the tooth & $2(0.8 \%)$ \\
\hline No surgical treatment; only non-surgical management at this stage & $6(2.5 \%)$ \\
\hline Other &
\end{tabular}

Table 4 Clinical practice on studied scenario

Sample size $(\mathrm{N}=228)$

Scenario $\mathrm{N}(\%)$

Cavity preparation choice (Figure 1)

\begin{tabular}{l|l}
\hline 1 & $47(20.6 \%)$ \\
\hline 2 & $123(53.9 \%)$ \\
\hline 3 & $4(1.8 \%)$ \\
\hline 4 & $22(9.6 \%)$ \\
\hline 5 & $4(1.8 \%)$ \\
\hline 6 & $22(9.6 \%)$ \\
\hline 7 & $6(2.6 \%)$ \\
\hline
\end{tabular}

Texture of dentine to stop excavation

\begin{tabular}{l|l} 
Soft & $9(3.9 \%)$ \\
\hline Leathery & $63(27.6 \%)$ \\
\hline Firm & $113(49.6 \%)$ \\
\hline Hard & $43(18.9 \%)$ \\
\hline Use of rubber dam & \multicolumn{2}{|l}{ T0 (17.5\%) } \\
\hline Never & $55(24.1 \%)$ \\
\hline Rarely &
\end{tabular}

and analysed. Respondents highlighted the use of magnification, disinfecting the cavity floor before restoration and ensuring that the margins of the cavity were free from caries.

Respondents were given a series of statements related to caries management and asked to score their level of agreement on a five-point Likert scale (Table 6). The highest proportion of respondents chose that they would 'agree' to give a diet sheet (33.9\%; $\mathrm{n}=81$ ), 'neither agree or disagree' to refer this patient to a hygienist (39.7\%; $\mathrm{n}=95)$, 'strongly disagreed' to carry out saliva testing $(37.2 \% ; \mathrm{n}=89)$ and 'strongly agreed' to advise use of fluoride adjuncts (46.4\%; $\mathrm{n}=111)$.
Sample size $(\mathrm{N}=228)$

Scenario

N (\%)

Use of rubber dam (cont.)

\begin{tabular}{l|l} 
Sometimes & $58(25.4 \%)$ \\
\hline Most of the time & $39(17.1 \%)$ \\
\hline Always & $36(15.8 \%)$
\end{tabular}

Material choice

\begin{tabular}{l|l} 
Resin composite & $43(18.9 \%)$ \\
\hline
\end{tabular}

\begin{tabular}{l|l}
\hline GIC & $32(14.0 \%)$ \\
\hline
\end{tabular}

\begin{tabular}{l|l}
\hline Amalgam & $54(23.7 \%)$ \\
\hline
\end{tabular}

\begin{tabular}{l|l}
\hline Zinc oxide eugenol & $1(0.4 \%)$
\end{tabular}

\begin{tabular}{l|l}
\hline Resin-modified GIC & $5(2.2 \%)$ \\
\hline Biodentine & $19(8.3 \%)$ \\
\hline $\begin{array}{l}\text { GIC }+ \text { resin composite as open } \\
\text { sandwich technique }\end{array}$ & $12(5.3 \%)$ \\
\hline $\begin{array}{l}\text { GIC }+ \text { resin composite as closed } \\
\text { sandwich technique }\end{array}$ & $47(20.6 \%)$ \\
\hline Other & $15(6.6 \%)$ \\
\hline
\end{tabular}

Strong themes emerged from the respondents' comments for both saliva testing and advising fluoride adjuncts (Table 7). Respondents highlighted a lack of knowledge, time constraint and lack of materials, when asked why they would not carry out saliva testing.

The respondents were presented with statements questioning whether other patientrelated factors would influence their management decision. The respondents reported to generally favour 'agree' for all three statements regarding the patient's financial situation $(32.6 \% ; n=77)$, their ability to access a dentist $(47.3 \% ; \mathrm{n}=113)$ and their age $(45.6 \% ; \mathrm{n}=109)$ influencing their decisions. 


\begin{tabular}{|c|c|c|}
\hline Themes & Sub-themes & Comments \\
\hline \multirow{3}{*}{ Adjuncts } & Magnification & - 'Loupes and illumination' \\
\hline & Light & - 'Clean EDJ well, periphery first, use good magnification and light, avoid contamination' \\
\hline & Other & $\begin{array}{l}\text { - 'Use intraoral camera to look at cavity close up for hue of pulp' } \\
\text { - 'Laser bandage on deep areas of the cavity. To help keep pulp vital' } \\
\text { - 'Air abrasion, polishing, matrix system'. }\end{array}$ \\
\hline \multirow{5}{*}{ Clinical techniques } & Cavity disinfection & $\begin{array}{l}\text { - 'Disinfection of cavity with chlorhexidine prior to restoration' } \\
\text { - 'Disinfect with sodium hypochlorite'. }\end{array}$ \\
\hline & Isolation & $\begin{array}{l}\text { - 'Rubber dam, remove undermined enamel, restore with matrix band' } \\
\text { - 'Rubber dam, disinfect with } 3 \% \mathrm{NaOHCl} \text {, selective caries removal'. }\end{array}$ \\
\hline & EDJ/ADJ cleaned & $\begin{array}{l}\text { - 'Removal of all caries on the Junction of enamel and dentine' } \\
\text { - 'Clear enamel dentine junction, remove unsupported enamel, leave base of affected dentine close to pulp'. }\end{array}$ \\
\hline & $\begin{array}{l}\text { Remove unsupported } \\
\text { enamel }\end{array}$ & $\begin{array}{l}\text { - 'Removal of any unsupported enamel' } \\
\text { - 'Use enamel hatchets around box margin, use fender wedge to protect the premolar, may use Chlorhexidine wash } \\
\text { after caries removal'. }\end{array}$ \\
\hline & $\begin{array}{l}\text { Matrix band and } \\
\text { wedge }\end{array}$ & $\begin{array}{l}\text { - 'Matrix band, wedge and contact point created' } \\
\text { - 'Wedging, sectional matrices, bond' }\end{array}$ \\
\hline \multicolumn{2}{|l|}{ Materials } & $\begin{array}{l}\text { - 'Use G5 under my composites' } \\
\text { - 'Sometimes would hand mix Biodentine and use as a lining' } \\
\text { - 'Selectively enamel etch. Bond pulpal floor. Flowable composite over area close to pulp'. }\end{array}$ \\
\hline
\end{tabular}

\section{Table 6 Clinical practice and willingness to practise}

Sample size $(\mathrm{N}=239)$

\begin{tabular}{|c|c|c|c|c|c|}
\hline \multirow[b]{2}{*}{ Practice } & \multicolumn{5}{|c|}{ Answer } \\
\hline & $\begin{array}{l}\text { Strongly } \\
\text { disagree N (\%) }\end{array}$ & Disagree N (\%) & $\begin{array}{l}\text { Neither agree or } \\
\text { disagree N (\%) }\end{array}$ & Agree N (\%) & $\begin{array}{l}\text { Strongly agree } \\
\mathrm{N}(\%)\end{array}$ \\
\hline Give this patient a diet sheet & $18(7.5 \%)$ & $33(13.8 \%)$ & $62(25.9 \%)$ & $81(33.9 \%)$ & $45(18.8 \%)$ \\
\hline Refer this patient to a hygienist & $7(2.9 \%)$ & $38(15.9 \%)$ & $95(39.7 \%)$ & $71(29.7 \%)$ & $28(11.7 \%)$ \\
\hline Carry out saliva testing on this patient & $89(37.2 \%)$ & $85(35.6 \%)$ & $48(20.1 \%)$ & $9(3.8 \%)$ & $8(3.3 \%)$ \\
\hline Advise that this patient uses fluoride adjuncts & $12(5.0 \%)$ & $4(1.7 \%)$ & $18(7.5 \%)$ & 94 (39.3\%) & $111(46.4 \%)$ \\
\hline
\end{tabular}

\section{Bivariate analysis}

Figure 2 shows which material was preferred among the three surgical treatment options: a) complete caries removal; b) partial caries removal and re-enter; and c) partial caries removal and not re-enter.

There was significant association $(\mathrm{FET}=53.33 ; \mathrm{p}<0.001)$ that resin composite, amalgam and a closed sandwich GIC-resin composite were used if the respondent opted for partial caries removal and not to re-enter. Amalgam was the preferred material if respondents chose complete caries removal and GIC was the preferred material if the respondent would re-enter following initial partial caries removal.

There was no significant association with the treatment choice and: a) how long the respondent had been qualified as a GDP $(\mathrm{F}=1.69 ; \mathrm{p}=0.17) ; \mathrm{b})$ their place of qualification $\left.\left(\chi^{2 \operatorname{lin}}=1.50 ; \mathrm{p}=0.95\right) ; \mathrm{c}\right)$ their age $(\mathrm{F}=2.01$; $\mathrm{p}=0.11)$; or $\mathrm{d})$ their $\operatorname{sex}\left(\chi^{2}=1.92 ; \mathrm{p}=0.17\right)$.
Table 7 Qualitative responses in respect of respondents' willingness to do saliva testing and to advise on fluoride

\begin{tabular}{|c|c|}
\hline Option & Response \\
\hline \multicolumn{2}{|l|}{ Willingness to do saliva testing } \\
\hline Lack of knowledge & $\begin{array}{l}\text { - 'Don't even know what this is' } \\
\text { - 'Never been told to do this'. }\end{array}$ \\
\hline Working environment limitations & $\begin{array}{l}\text { - 'No access to this or funding in NHS practice' } \\
\text { - 'Maybe if I worked privately'. }\end{array}$ \\
\hline Lack of materials & $\begin{array}{l}\text { - 'Don't have kits available' } \\
\text { - 'Useful tool but not available at my practice'. }\end{array}$ \\
\hline \multicolumn{2}{|l|}{ Advice on fluoride } \\
\hline $\begin{array}{l}\text { Specific fluoride delivery } \\
\text { methods }\end{array}$ & $\begin{array}{l}\text { - 'Fluoride (NaF) toothpaste, NaF mouthwash' } \\
\text { - 'Fluoride mouthwash and toothpaste usage at differing times of the day' }\end{array}$ \\
\hline Evidence-based & $\begin{array}{l}\text { - 'Delivering better oral health guidelines' } \\
\text { - 'Fluoride protects against caries'. }\end{array}$ \\
\hline Fluoride concentrations & $\begin{array}{l}\text { - 'Duraphat } 5000 \text { ppm' } \\
\text { - '2800 ppm fluoride toothpaste'. }\end{array}$ \\
\hline
\end{tabular}




\section{Fig. 2 The materials chosen for different restorative options}

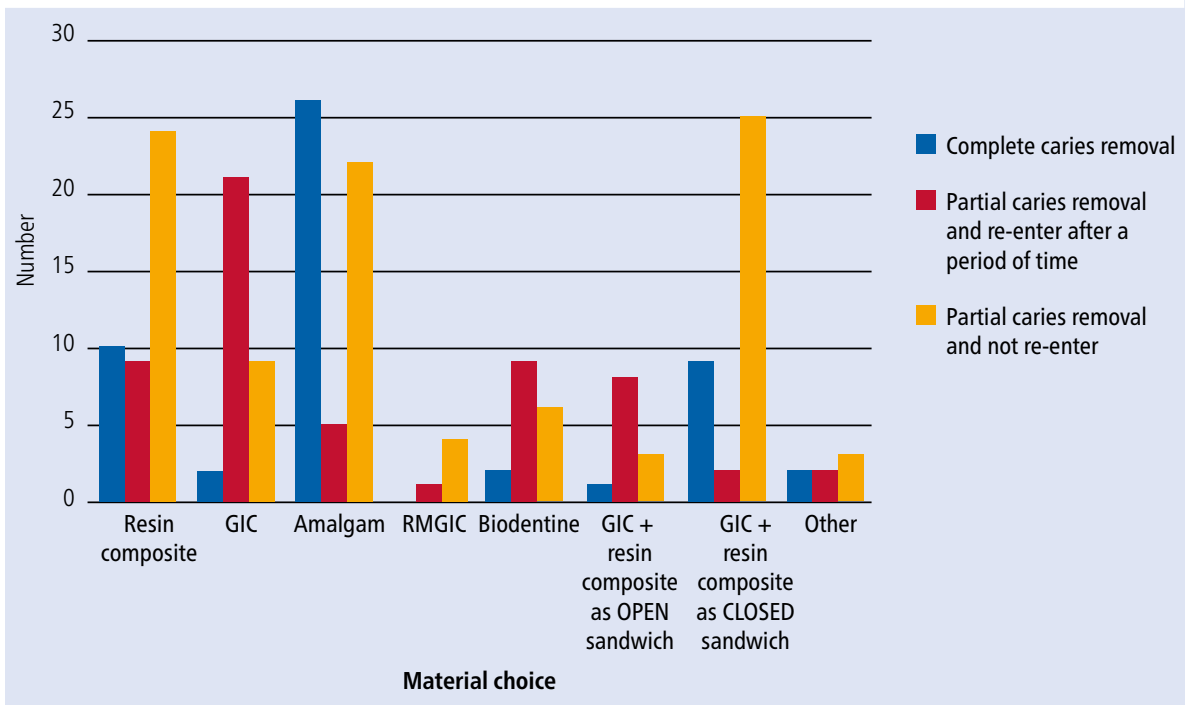

Table 8 Association of level of willingness to carry out MID good practice with postgraduate course, work place and qualification year

\begin{tabular}{|c|c|c|c|}
\hline Method & Postgraduate course & Work place & Qualification year \\
\hline Rubber dam & $\begin{array}{l}\chi^{2 \operatorname{lin}}=30.15 \\
p=<0.001\end{array}$ & $\begin{array}{l}\chi^{2}=81.16 \\
p=<0.001\end{array}$ & $\begin{array}{l}F=0.67 \\
p=0.62\end{array}$ \\
\hline Diet sheet & $\begin{array}{l}\chi^{2 \operatorname{lin}}=0.14 \\
p=0.73\end{array}$ & $\begin{array}{l}\chi^{2}=17.49 \\
p=0.13\end{array}$ & $\begin{array}{l}F=0.66 \\
p=0.62\end{array}$ \\
\hline Hygienist referral & $\begin{array}{l}\chi^{2 \operatorname{lin}}=3.05 \\
p=0.09\end{array}$ & $\begin{array}{l}\mathrm{FET}=34.91 \\
p=<0.001\end{array}$ & $\begin{array}{l}F=2.47 \\
p=0.04\end{array}$ \\
\hline Saliva test & $\begin{array}{l}\chi^{2 \operatorname{lin}}=4.72 \\
p=0.03\end{array}$ & $\begin{array}{l}\mathrm{FET}=19.80 \\
p=0.04\end{array}$ & $\begin{array}{l}F=3.38 \\
p=0.01\end{array}$ \\
\hline Fluoride & $\begin{array}{l}\chi^{2 \operatorname{lin}}=2.46 \\
p=0.13\end{array}$ & $\begin{array}{l}\mathrm{FET}=4.91 \\
\mathrm{p}=0.97\end{array}$ & $\begin{array}{l}F=1.10 \\
p=0.36\end{array}$ \\
\hline
\end{tabular}

There was a significant association $\left(\chi^{2}=8.54\right.$; $\mathrm{p}=0.03)$ if the respondent had undergone a postgraduate course that covered caries management to treatment choice. Further statistical analysis showed that there was a significant association $\left(\chi^{2}=6.27 ; p=0.01\right)$, that those respondents who had postgraduate training chose a partial caries removal technique.

It was interesting to note that respondents working exclusively or mostly in NHS practices were more likely to always use rubber dam $\left(\chi^{2}=81.16 ; \mathrm{p}<0.001\right)$ when treating a deep carious lesion.

There were significant associations that those who had postgraduate training were more likely to score 'always' to use rubber dam and more likely to score 'never' use rubber dam if they had not undergone postgraduate training (Table 8) $\left(\chi^{2 \text { lin }}=30.15 ; \mathrm{p}<0.001\right)$.

There was a significant correlation of those respondents that had postgraduate training in MID caries management to those that chose 'strongly agree' to feeling confident in having the knowledge and offering MID $\left(\chi^{2}=21.20\right.$; $\mathrm{p}<0.001)$. that GDPs are now implementing some MID principles in their clinical practice.

\section{Treatment choice}

The majority of respondents (70\%) adopted a partial caries removal strategy, either partial caries removal without re-entering or stepwise technique. This was a significant improvement compared to what had been reported in other studies below. Weber et al. $(2011)^{18}$ reported that $71.1 \%$ of dentists preferred complete caries removal compared to $17.6 \%$ preferring stepwise excavation. Oen et al. $(2007)^{19}$ reported that $62 \%$ of US dentists preferred total caries removal, even when there was a risk of exposure. A recent meta-analysis found that more than $50 \%$ of dentists rejected using MID strategies. ${ }^{4}$

There is an element of unpredictability with the success in maintaining pulpal vitality with partial caries removal, such as the risks of pulpal necrosis. However, when this is carried out by appropriately skilled operators, using appropriate materials and time, it would be a viable management option. It is perhaps due to a lack of confidence in the contemporary evidence-based strategies, a fear of litigation regarding 'neglect' by leaving caries, or lack of knowledge in MID which make GDPs reluctant to change what they've always known to work, with almost one-third of respondents opting for traditional treatments options of complete caries removal, root canal treatment or extraction.

With $86 \%$ of respondents claiming 'not always' using rubber dam when attempting to restore a deep carious lesion, it is unlikely that effective moisture control might be attainable, thus increasing the risk of treatment failure. The MID techniques of partial caries removal to maintain tooth vitality require a reliable coronal seal and preferably an adhesive restoration. This scenario carries a risk that ongoing treatment might be required, so rubber dam should already have been placed. The choice of respondents working in NHS/mostly NHS practices to use rubber-dam isolation is promising and encouraging, (61.7\%) that regardless of the clinical operational environment, this crucial step can still be undertaken. It will be interesting to see if other studies conducted in different paradigms might demonstrate a similar trend.

\section{Materials}

The access to adhesive materials, especially resin composite and Biodentine, which are more costly and will take up more clinical time than to use amalgam, is likely to have influenced its incidence of use, with amalgam still being favoured by those 
in NHS practice $\left(\chi^{2}=34.98 ; \mathrm{p}<0.001\right)$. With the Minamata Treaty advocating phase-down of the use of dental amalgam, GDPs will soon be obligated to manage this material irrespective of their working environment. Some undergraduate programmes in the UK have stopped teaching the use of amalgam, instead focusing on MID and adhesive dentistry. With amalgam being taught and used less at undergraduate institutes and with environmental concerns over its disposal, its use is likely to continue to decrease. The onus is on the GDP to retrain themselves in order to be able to apply MID as a modern approach to a population with ever-changing needs and demands. A number of university postgraduate programmes have been developed for this purpose.

\section{Influencing factors}

Offering MID can sometimes mean performing lengthier procedures, using more expensive materials and examining/reviewing the patient more frequently, resulting in a less cost-effective approach by GDPs. These reasons are likely to be why GDPs strongly disagreed in carrying out saliva testing or using materials such as Biodentine. Pilot NHS contracts have been developed so to focus on preventative care of the patient and so the topic of remuneration in NHS/mixed practice settings is certainly positively changing.

The ability to use materials that are better suited to follow MID recommendations are often dictated by patient ability to pay for them. The statistically significant association of 'GP score' with work place, showed that those working in majority private practice were able to implement more MID principles.

\section{If the study was to be repeated and future studies}

A rerun of this study could include questions to determine what deters GDPs from implementing MID principles in their practice, as it would be interesting to truly conclude if the remuneration system in the UK and lack of access to suitable materials and instruments negatively influence practitioners. A future follow-up study to investigate GDPs' reasons for lack of use of rubber dam would be interesting.
There are some limitations of the use of 'GP score'; however, it allowed investigation of correlations/significant predictors of those respondents who answered according to the 'GP score' classification. MID is considered multifaceted and multi-factorial and there is not a sole correct way to address this scenario. MID recommendations, as per ICCC itself, ${ }^{2}$ suggests different options in the management of deep carious lesions. The three suggested dimensions from the PC analysis reflect an underlying clinical phenomenon, especially of those in group 1 and 2. Respondents of group 1 answered to reflect that of generally highly endorsed clinical aspects of MID good practice, while group 2 answered with elements that are likely to reflect on the type of working environment and included two factors that generally had the least endorsement. The difference in performance in these different areas may indicate where improvements can be made and how educational interventions can be directed.

To supplement this, the pilot study conducted on different specialists, with the hope of obtaining a single gold standard of management, interestingly showed that there was no homogenous response among them. A future study among specialists would be interesting to understand rationales for their management decisions.

\section{Conclusion}

This study demonstrated that there is an inconsistent management protocol in relation to the management of a deep carious lesion. It illustrated that the practice of aspects of MID among UK GDPs is being adopted in general. However, GDPs (unless newly qualified) may benefit from further training to be familiar with the concepts of MID and thereby be able to apply this evidence-based contemporary approach to effective caries management. The implementation of MID is influenced by external factors including the GDPs working environment and the patient's financial position. GDPs who have undertaken postgraduate training felt more confident in offering MID, so there is a clear need for further education to ensure that this is more widely understood and applied in practice.
Ethics declaration

The authors declare no conflicts of interest.

\section{Author contributions}

Sheena Patel helped with data collection, data analysis and the writing of the manuscript, Peter Fine helped with data analysis and the writing of the manuscript. Mandeep Shukla helped with the writing of the manuscript. Robert Blizard helped with data analysis and the writing of manuscript. Albert Leung helped with the writing of the manuscript.

\section{References}

1. Marsh P D. Dental plaque as a biofilm and a microbial community - implications for health and disease. BMC Oral Health 2006; DOI: 10.1186/1472-6831-6-S1-S14.

2. Banerjee A., Frencken J E, Schwendicke F, Innes, N P T. Contemporary operative caries management: consensus recommendations on minimally invasive caries removal. Br Dent J 2017; 223: 215-222.

3. Marsh P D. Microbial Ecology of Dental Plaque and its Significance in Health and Disease. Adv Dent Res 1994; 8: 263-271.

4. Schwendicke F. Göstemeyer G. Understanding dentists management of deep carious lesions in permanent teeth: a systematic review and meta-analysis. Implement Sci 2016; 11: 142

5. Schwendicke F, Meyer-Lueckel H, Dörfer C, Paris S. Failure of incompletely excavated teeth - A systematic review. J Dent 2013; 41: 569-580.

6. Murdoch-Kinch C, Mclean M E. Minimally invasive dentistry. J Am Dent Assoc 2003; 134: 87-95.

7. Black G V. A Work on Operative Dentistry. 2nd ed. Chicago: Medico-Dental Publishing Company, 1908.

8. Fusayama T. The process and results of revolution in dental caries treatment. Int Dent J 1997; 47: 157-166.

9. Elderton R J. Overtreatment with restorative dentistry: when to intervene? Int Dent J 1993; 43: 17-24.

10. Frencken J E., Peters M C, Manton D J, Leal S C, Gordan V $V$, Eden E. Minimal intervention dentistry for managing dental caries - a review. Int Dent J 2012: 62: 223-243.

11. Banerjee A, Doméjean S. The Contemporary Approach to Tooth Preservation: Minimum Intervention (MI) Caries Management in General Practice. Prim Dent J 2013; 2: 30-37.

12. Mount $\mathrm{G} \mathrm{J}$. Minimal intervention dentistry: rationale of cavity design. Oper Dent 2003; 28: 92-99.

13. Innes N, Frencken J, Bjørndal L et al. Managing Carious Lesions: Consensus Recommendations on Terminology. Adv Dent Res 2016; 28: 49-57.

14. Mirsiaghi F, Leung A, Fine P, Blizard R, Louca C. An investigation of general dental practitioners' understanding and perceptions of minimally invasive dentistry. Br Dent J 2018; 225: 420-424.

15. Cohen L, Manion L, Morrison K. Research methods in education. London: Routledge, 2009.

16. Likert R. A Technique for the Measurement of Attitudes. Archives of Psychology 1932; 140: 5-55.

17. Statistics How To. Cronbach's Alpha: Simple Definition, Use and Interpretation. 2022. Available at https:// www.statisticshowto.com/probability-and-statistics/ statistics-definitions/cronbachs-alpha-spss/ (accessed January 2022).

18. Weber C M, Alves L S, Maltz M. Treatment decisions for deep carious lesions in the Public Health Service in Southern Brazil. J Public Health Dent 2011; 71: 265-270.

19. Oen K T, Thompson V P, Vena D et al. Attitudes and expectations of treating deep caries: A PEARL network survey. Gen Dent 2007; 55: 197-203. or other third party material in this article are included in the article's Creative Commons licence, unless indicated otherwise in a credit line to the material. If material is not included in the article's Creative Commons licence and your intended use is not permitted by statutory regulation or exceeds the permitted use, you will need to obtain permission directly from the copyright holder. To view a copy of this licence, visit http://creativecommons.org/licenses/by/4.0.

(c) The Author(s) 2021 